\title{
Influences of Slip Velocity and Induced Magnetic Field on MHD Stagnation-Point Flow and Heat Transfer of Casson Fluid over a Stretching Sheet
}

\author{
Mohamed Abd El-Aziz $\mathbb{D}^{1}$ and Ahmed A. Afify $\mathbb{D}^{2}$ \\ ${ }^{1}$ Department of Mathematics, Faculty of Science, King Khalid University, Abha 9004, Saudi Arabia \\ ${ }^{2}$ Department of Mathematics, Deanship of Educational Services, Qassim University, P.O. Box 6595, Buraidah 51452, Saudi Arabia \\ Correspondence should be addressed to Mohamed Abd El-Aziz; m_abdelaziz999@yahoo.com
}

Received 3 March 2018; Revised 3 May 2018; Accepted 22 May 2018; Published 11 July 2018

Academic Editor: Efstratios Tzirtzilakis

Copyright (C) 2018 Mohamed Abd El-Aziz and Ahmed A. Afify. This is an open access article distributed under the Creative Commons Attribution License, which permits unrestricted use, distribution, and reproduction in any medium, provided the original work is properly cited.

\begin{abstract}
The steady MHD boundary layer flow near the stagnation point over a stretching surface in the presence of the induced magnetic field, viscous dissipation, magnetic dissipation, slip velocity phenomenon, and heat generation/absorption effects has been investigated numerically. The Casson fluid model is used to characterize the non-Newtonian fluid behavior. The governing partial differential equations using appropriate similarity transformations are reduced into a set of nonlinear ordinary differential equations, which are solved numerically using a shooting method with fourth-order Runge-Kutta integration scheme. Comparisons with the earlier results have been made and good agreements were found. Numerical results for the velocity, induced magnetic field, temperature profiles, skin friction coefficient, and Nusselt number are presented through graphs and tables for various values of physical parameters. Results predicted that the magnetic parameter with $\alpha<1$ has the tendency to enhance the heat transfer rate, whereas the reverse trend is seen with $\alpha>1$. It is also noticed that the rate of heat transfer is a decreasing function of the reciprocal of a magnetic Prandtl number, whereas the opposite phenomenon occurs with the magnitude of the friction factor.
\end{abstract}

\section{Introduction}

The steady MHD boundary layer flow of an incompressible viscous fluid near the stagnation point has received great attention owing to their wide applications in the various fields of industry and engineering applications such as design of thrust bearings, transpiration cooling, and aerodynamics extrusion of plastic sheets. The classical two-dimensional stagnation point flow on a flat plate was first studied by Hiemenz [1]. Hiemenz problem was extended to the axisymmetric case by Homann [2]. The impact of an external magnetic field on Hiemenz flow of an electrically conducting fluid was investigated by some researchers [3-7]. Recently, the MHD stagnation point flow past a stretching sheet with the influences of radiation, velocity, and thermal slip phenomena was analyzed by Khan et al. [8].

In recent years, it has been observed that a number of industrial fluids such as molten plastics, polymeric liquids, foodstuff, and slurries exhibit non-Newtonian fluid behavior. For non-Newtonian fluids, various models have been proposed. The vast majorities of non-Newtonian fluid models are concerned with simple models like the power law and grade two or three etc. Reviews of non-Newtonian fluid problems have been presented in [9-15]. There is another non-Newtonian fluid model, known as the Casson fluid model. The Casson fluid can be defined as a shear thinning the liquid which is assumed to have an infinite viscosity at zero the rate of shear, a yield stress below where no flow occurs, and a zero viscosity at an infinite rate of shear. This fluid has significant applications in polymer processing industries and biomechanics. Boundary layer flow of Casson fluid over different geometries is considered by many authors [16-21]. Recently, Khan et al. [22] numerically discussed the influence of chemical reaction on an unsteady Casson fluid over the stretching surface. 
The induced magnetic field has received considerable interest owing to its use in many scientific and technological phenomena, for example, in MHD energy generator systems and magnetohydrodynamic boundary layer control technologies. The influence of induced magnetic field on unsteady MHD free convective flow over a semi-infinite vertical surface was investigated by Kumar and Singh [23]. Beg et al. [24] investigated the hydromagnetic convection flow of a Newtonian, electrically conducting fluid over a translating, nonconducting plate with the aligned magnetic field. The impacts of a transverse magnetic field and magnetic induction on MHD natural convection boundary layer flow over an infinite vertical flat plate were analytically studied by Ghosh et al. [25]. Ali et al. [26] discussed the effect of an induced magnetic field on boundary layer stagnationpoint flow over a stretching surface. Iqbal et al. [27] studied the combined effects entropy generation and induced the magnetic field on stagnation point flow and heat transfer due to nanofluid towards a stretching sheet.

Slip boundary condition is a very developed phenomenon which includes the nonadherence of fluids to surfaces. Fluids exhibiting slip are important in the areas of technology and industry such as in the polishing of artificial heart valves and internal cavities. In this context, Kundsen number $K_{n}$ is a deciding coefficient, which is a measure of the molecular mean free path to characteristic length. When Knudsen number is very small, no slip is noticed between the surface and the fluid and is in tune with the essence of continuum mechanics. Beavers and Joseph [28] proposed a slip flow boundary condition. The influences of thermal radiation, Newtonian heating, and slip velocity phenomenon on MHD flow and heat transfer past a permeable stretching sheet were numerically studied by Afify et al. [29]. The impacts of slip flow, convective boundary condition, and thermal radiation on mixed convection heat and mass transfer flow over a vertical surface were numerically discussed by Uddin et al. [30]. The impact of viscous dissipation and velocity slip phenomenon on ferrofluid flows past a slender stretching sheet was investigated by Ramana Reddy et al. [31]. The influence of nonuniform heat source and slip flow on MHD nanofluid flow past a slandering stretching sheet was analyzed by Ramana Reddy et al. [32]. Recently, Hosseini et al. [33] analyzed the flow and heat transfer characteristics of an unsteady flow past a permeable stretching sheet in the presence of the velocity slip factor and temperature jump influences.

To the best of the author's knowledge, this work has not been previously studied in the scientific research. The main aim of this paper is to analyze the MHD stagnation-point flow and heat transfer of a non-Newtonian fluid known as Casson fluid over a stretching surface in the presence of the induced magnetic field, viscous dissipation, velocity slip boundary condition, and heat generation/absorption effects. Diagrams and tables are presented and discussed for various physical parameters entering into the problem.

\section{Mathematical Formulation}

Consider the steady magnetohydrodynamic (MHD) flow of a non-Newtonian Casson fluid near the stagnation point over

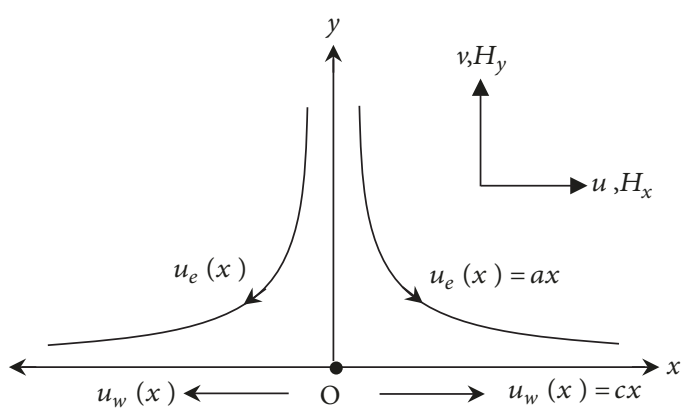

Figure 1: Physical model and coordinate system.

a stretching surface coinciding with the plane $y=0$, the flow being confined to $y>0$. Two equal and opposite forces are applied along the $\mathrm{x}$-axis so that the surface is stretched keeping the origin fixed. The effect of the induced magnetic field is taken into account. The flow configuration is shown in Figure 1. The viscous dissipation, magnetic dissipation, and heat generation/absorption terms are included in the energy equation. The rheological equation of state for an isotropic and incompressible flow of Casson fluid can be expressed as follows (Eldabe and Salwa [34]):

$$
\tau_{i j}= \begin{cases}2\left(\mu_{B}+\frac{p_{y}}{\sqrt{2 \pi}}\right) e_{i j}, & \pi>\pi_{c} \\ 2\left(\mu_{B}+\frac{p_{y}}{\sqrt{2 \pi_{c}}}\right) e_{i j}, & \pi<\pi_{c}\end{cases}
$$

where $\mu_{B}$ is the plastic dynamic viscosity of the nonNewtonian fluid, $p_{y}$ is the yield stress of fluid, $\pi$ is the product of the component of deformation rate by itself, namely, $\pi=$ $e_{i j} e_{i j}, e_{i j}$ is the, $(i, j)$-the component of the deformation rate, and $\pi_{c}$ is a critical value of $\pi$ based on non-Newtonian model. Under the above-mentioned assumptions and the boundary layer approximations, the governing equations of Casson fluid can be written as (Cowling [35])

$$
\begin{aligned}
& \frac{\partial u}{\partial x}+\frac{\partial v}{\partial y}=0 \\
& \frac{\partial H_{x}}{\partial x}+\frac{\partial H_{y}}{\partial y}=0 \\
& u \frac{\partial u}{\partial x}+v \frac{\partial u}{\partial y} \\
& =v\left(1+\frac{1}{\gamma}\right) \frac{\partial^{2} u}{\partial y^{2}}+\frac{\mu_{e}}{\rho}\left[H_{x} \frac{\partial H_{x}}{\partial x}+H_{y} \frac{\partial H_{x}}{\partial y}\right] \\
& +\left[u_{e} \frac{d u_{e}}{d x}-\frac{\mu_{e}}{\rho} H_{e} \frac{d H_{e}}{d x}\right] \\
& u \frac{\partial H_{x}}{\partial x}+v \frac{\partial H_{x}}{\partial y}-H_{x} \frac{\partial u}{\partial x}-H_{y} \frac{\partial u}{\partial y}=\eta_{0} \frac{\partial^{2} H_{x}}{\partial y^{2}}
\end{aligned}
$$




$$
\begin{aligned}
u \frac{\partial T}{\partial x}+ & v \frac{\partial T}{\partial y} \\
= & \alpha_{0} \frac{\partial^{2} T}{\partial y^{2}}+\frac{v}{C_{p}}\left(1+\frac{1}{\gamma}\right)\left(\frac{\partial u}{\partial y}\right)^{2}+\frac{1}{\sigma \rho C_{p}}\left(\frac{\partial H_{x}}{\partial y}\right)^{2} \\
& +\frac{Q_{0}}{\rho C_{p}}\left(T-T_{\infty}\right)
\end{aligned}
$$

Subject to the boundary conditions:

$$
\begin{aligned}
u & =u_{w}(x)+N\left(1+\frac{1}{\gamma}\right) \frac{\partial u}{\partial y}, \\
v & =0, \\
T & =T_{w}(x)=T_{\infty}+b\left(\frac{x}{L}\right)^{2}, \\
\frac{\partial H_{x}}{\partial y} & =H_{y}=0
\end{aligned}
$$

$$
\text { at } y=0
$$

$$
\begin{aligned}
u & =u_{e}(x)=a x, \\
H_{x} & =H_{e}(x)=H_{0}\left(\frac{x}{L}\right), \\
T & =T_{\infty}
\end{aligned}
$$$$
\text { as } y \longrightarrow \infty
$$

$\alpha_{0}=k / \rho C_{p}$ is the thermal diffusivity of the fluid, $\eta_{0}$ is magnetic diffusivity, $\mu_{e}$ is magnetic permeability, $L$ is the characteristic length of the stretching surface, $N$ is the velocity slip factor, $v=\mu / \rho$ is kinematics viscosity, $H_{0}$ is an estimation of the uniform magnetic field at the upstream infinity, $u_{e}(x)=a x$ is the velocity of the flow outside the boundary layer, $u_{w}(x)=c x$ is the velocity of the stretching sheet with $c$ and $a$ being the positive constants determining the strength of the stagnation point and stretching rate, and $H_{e}(x)=H_{0}(x / L)$ is the magnetic field at the edge of the boundary layer. Also, $(u, v)$ and $\left(H_{x}, H_{y}\right)$ are the velocity and magnetic components in $(x, y)$ directions, respectively. We introduce the following dimensionless variables $[36,37]$ :

$$
\begin{aligned}
\eta & =\sqrt{\frac{c}{v}} y, \\
u & =c x f^{\prime}(\eta), \\
v & =-\sqrt{c v} f(\eta), \\
\theta(\eta) & =\frac{T-T_{\infty}}{T_{w}-T_{\infty}} \\
H_{x} & =\left(\frac{x}{L}\right) H_{0} g^{\prime}(\eta), \\
H_{y} & =-\sqrt{\frac{v}{c L^{2}}} H_{0} g(\eta)
\end{aligned}
$$

Equations (2) and (3) are automatically satisfied. In view of relation (8), (3)-(7) are reduced to

$$
\begin{aligned}
& \left(1+\frac{1}{\gamma}\right) f^{\prime \prime \prime}+f f^{\prime \prime}-f^{\prime 2}+\alpha^{2} \\
& +\beta\left(g^{\prime 2}-g g^{\prime \prime}-1\right)=0 \\
& \lambda g^{\prime \prime \prime}+f g^{\prime \prime}-f^{\prime \prime} g=0 \\
& \frac{1}{\operatorname{Pr}} \theta^{\prime \prime}-2 f^{\prime} \theta+f \theta^{\prime}+E c\left(1+\frac{1}{\gamma}\right)\left(f^{\prime \prime}\right)^{2} \\
& +\lambda \beta E c\left(g^{\prime \prime}\right)^{2}+\delta \theta=0
\end{aligned}
$$

With boundary conditions

$$
\begin{aligned}
f^{\prime}(0) & =1+\chi\left(1+\frac{1}{\gamma}\right) f^{\prime \prime}(0), \\
f(0) & =0, \\
g^{\prime \prime}(0) & =0, \\
g(0) & =0 \\
\theta(0) & =1 \\
f^{\prime}(\infty) & \longrightarrow \alpha, \\
g^{\prime}(\infty) & \longrightarrow 1, \\
\theta(\infty) & \longrightarrow 0
\end{aligned}
$$

Here prime denotes differentiation with respect to $\eta$. $f$ is similarity function, $\theta$ is dimensionless temperature, and $f^{\prime}$ and $g^{\prime}$ are the velocity and the induced magnetic field profiles, respectively. $\operatorname{Pr}=v / \alpha_{0}$ is Prandtl number, $\delta=$ $Q_{0} / c \rho C_{p}$ is the heat generation/absorption parameter, $\beta=$ $\left(\mu_{e} / \rho\right)\left(H_{o} / c L\right)^{2}$ is the magnetic parameter, $\chi=\sqrt{c / v} N$ is the slip parameter, $E c=c^{2} L^{2} / b C_{p}$ is Eckert number, $\alpha=a / c$ is the stretching parameter, and $\lambda=\eta_{0} / v$ is the reciprocal of the magnetic Prandtl number, respectively. It is should be noticed that $\gamma \longrightarrow \infty$ indicates a Newtonian fluid. The quantities of physical interest in this problem are the skin friction coefficient and the local Nusselt number, which are defined as

$$
\begin{aligned}
C_{w} & =\frac{\tau_{w}}{\rho u_{w}^{2}}, \\
N u_{x} & =\frac{x q_{w}}{k\left(T_{w}-T_{\infty}\right)}
\end{aligned}
$$

where $\tau_{w}$ is the skin friction or shear stress along the stretching surface and $q_{w}$ is the heat transfer from the surface which are

$$
\begin{aligned}
& \tau_{w}=\left(\mu_{B}+\frac{p_{y}}{\sqrt{2 \pi_{c}}}\right)\left(\frac{\partial u}{\partial y}\right)_{y=0}, \\
& q_{w}=-k\left(\frac{\partial T}{\partial y}\right)_{y=0}
\end{aligned}
$$


Using (8), (13), and (14), the dimensionless form of skin friction and local Nusselt number become

$$
\begin{aligned}
\operatorname{Re}_{x}^{1 / 2} C_{f} & =\left(1+\frac{1}{\gamma}\right) f^{\prime \prime}(0) \\
\frac{N u_{x}}{\operatorname{Re}_{x}^{1 / 2}} & =-\theta^{\prime}(0)
\end{aligned}
$$

where $\operatorname{Re}_{x}=x u_{w} / v$ is the local Reynolds number.

\section{Numerical Procedure}

The nonlinear differential equations (9)-(11) along with the boundary conditions (12) form a two-point boundary value problem (BVP) and are solved using shooting method, by converting into an initial value problem (IVP). In this method, the system of (9)-(11) is converted into the set of following the first-order system:

$$
\begin{aligned}
& f^{\prime}=p, \\
& p^{\prime}=q, \\
& g^{\prime}=s, \\
& s^{\prime}=n, \\
& q^{\prime}=\left(\frac{\gamma}{\gamma+1}\right)\left[p^{2}-f q-\alpha^{2}-\beta\left(s^{2}-g n-1\right)\right] \\
& n^{\prime}=\frac{1}{\lambda}(q g-f n) \\
& \theta^{\prime}=z, \\
& z^{\prime}=\operatorname{Pr}\left(2 p \theta-f z-E c\left(1+\frac{1}{\gamma}\right) q^{2}-\lambda \beta E c n^{2}+\delta \theta\right)
\end{aligned}
$$

with the initial conditions,

$$
\begin{aligned}
& p(0)=1+\left(1+\frac{1}{\gamma}\right) q(0), \\
& f(0)=0, \\
& g(0)=0 \\
& n(0)=0 \\
& \theta(0)=1
\end{aligned}
$$

To solve (17)-(19) with (20) as an IVP we must need the values for $q(0)$, i.e., $f^{\prime \prime}(0), s(0)$ i.e., $g^{\prime}(0)$ and $z(0)$ i.e., $\theta^{\prime}(0)$ but no such values are given. The initial guess values for $f^{\prime \prime}(0)$, $g^{\prime}(0)$, and $\theta^{\prime}(0)$ are chosen and the fourth-order Runge-Kutta integration scheme is applied to obtain a solution. Then we compare the calculated values of $f^{\prime}(\eta), g^{\prime}(\eta)$, and $\theta(\eta)$ at $\eta_{\infty}(=80)$ with the given boundary conditions $f^{\prime}\left(\eta_{\infty}\right)=\alpha$, $g^{\prime}\left(\eta_{\infty}\right)=1$, and $\theta\left(\eta_{\infty}\right)=0$ and adjust the values of $f^{\prime \prime}(0), g^{\prime}(0)$, and $\theta^{\prime}(0)$ using "secant method" to give better approximation for the solution. The step-size is taken as $\Delta \eta=$
TABLE 1: Skin friction coefficient $f^{\prime \prime}(0)$ for different values of $\alpha=$ $a / c, \beta=0$, and $\gamma \longrightarrow \infty$.

\begin{tabular}{ccccc}
\hline$\alpha=\frac{a}{c}$ & $\begin{array}{c}\text { Mahapatra } \\
\text { and Gupta } \\
{[38]}\end{array}$ & $\begin{array}{c}\text { Ishak et al. } \\
{[39]}\end{array}$ & $\begin{array}{c}\text { Ali } \text { et al. } \\
{[26]}\end{array}$ & Present study \\
\hline 0.1 & -0.9694 & -0.9694 & -0.9694 & -0.969386 \\
0.2 & -0.9181 & -0.9181 & -0.9181 & -0.918107 \\
0.5 & -0.6673 & -0.6673 & -0.6673 & -0.667263 \\
2.0 & 2.0175 & 2.0175 & 2.0175 & 2.017500 \\
3.0 & 4.7293 & 4.7294 & 4.7293 & 4.729280 \\
\hline
\end{tabular}

0.01 . The process is repeated until we get the results correct up to the desired accuracy of $10^{-5}$ level, which fulfills the convergence criterion. In order to assess the accuracy of the numerical method, we have compared the present results of $f^{\prime \prime}(0)$ for different values of $\alpha$ with $\beta=0$ and $\gamma \rightarrow \infty$ in the absence of the energy equation versus the previously published data of Mahapatra and Gupta [38], Ishak et al. [39], and Ali et al. [26]. The comparison is listed in Table 1 and found in excellent agreement.

\section{Results and Discussions}

The nonlinear ordinary differential equations (9)-(11) subject to the boundary conditions (12) are solved numerically by using a shooting method with fourth-order Runge-Kutta integration scheme. The numerical results of the friction factor and the heat transfer rate are tabulated in Tables 2-4, for both cases of Newtonian and non-Newtonian flows with the pertinent parameters. It is revealed from the Table 2 that the rate of heat transfer increases by increasing magnetic parameter $\beta$ with $\alpha<1$, whereas the opposite results occur with the magnitude of the friction factor for both cases of Newtonian and non-Newtonian flows. On the other hand, it is observed that the friction factor and the rate of heat transfer decrease by increasing magnetic parameter $\beta$ with $\alpha>1$ for both cases. It is observed from this Table 3 that the rate of heat transfer reduces with an increase in reciprocal of the magnetic Prandtl number $\lambda$, whereas the opposite results occur with the magnitude of the friction factor for both cases. From Table 4, as compared to the case of no heat generation/absorption $\delta=0$ the heat transfer rate is enhanced owing to heat absorption $\delta<0$, whereas the opposite results hold with heat generation $\delta>0$ for both cases. This behavior is in tune with the result for temperature profile shown in Figure 14. From this figure, we observe that the temperature distribution is lower throughout the boundary layer for negative value of $\delta$ (heat absorption) and higher for positive value of $\delta$ (heat generation). Figures 2-18 are drawn in order to see the influences of magnetic parameter $\beta$ a reciprocal of the magnetic Prandtl number $\lambda$ heat generation/absorption parameter $\delta$ stretching parameter $\alpha$ slip parameter $\chi$ and Eckert number $E c$ on the velocity, induced magnetic field and temperature profiles for the steady two-dimensional stagnation-point flow of Newtonian and non-Newtonian fluids along a linearly stretching surface. 


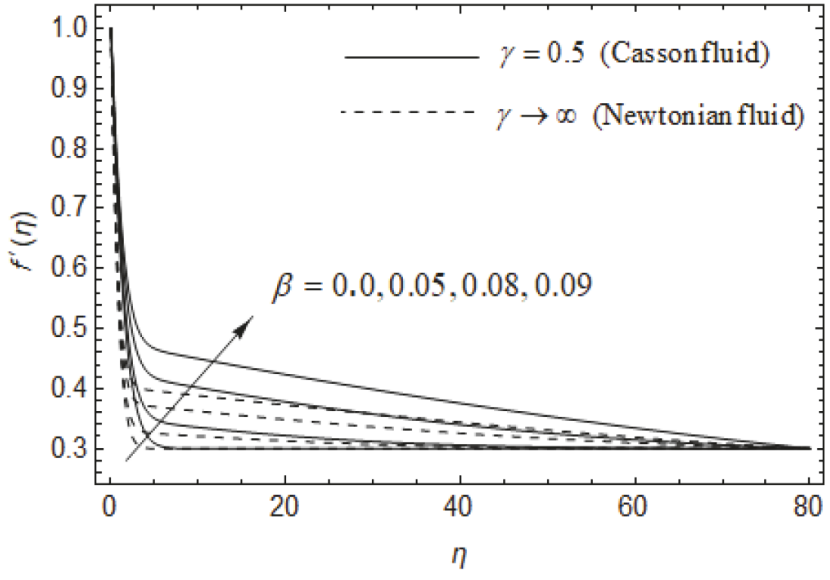

(a) Velocity profiles for various values of $\beta$ and $\gamma$ when $\chi=0.0, \lambda=100$, $\alpha=0.3, \delta=0.2$, and $\operatorname{Pr}=1$

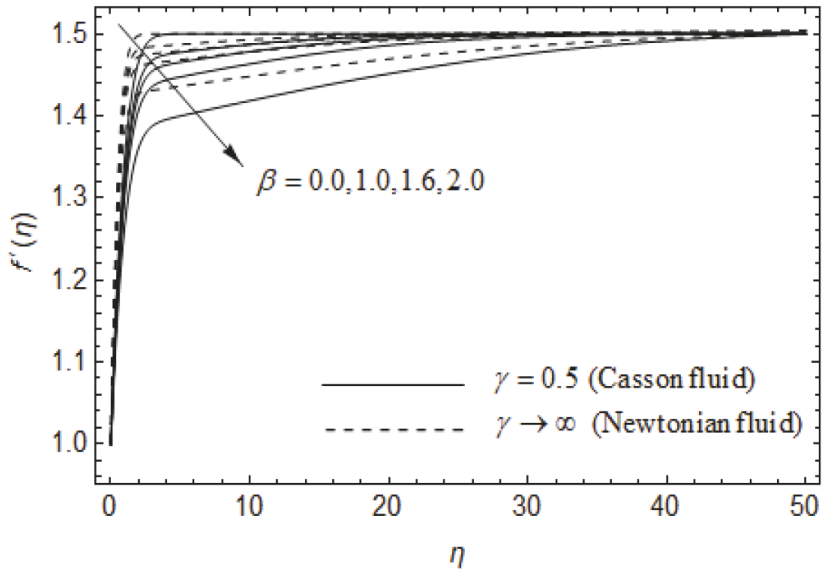

(b) Velocity profiles for various values of $\beta$ and $\gamma$ when $E c=\chi=0.0$, $\lambda=100, \alpha=1.5, \delta=0.2$, and $\operatorname{Pr}=1$

FIgURE 2

TABLE 2: Variation of $\operatorname{Re}_{\mathrm{x}}{ }^{1 / 2} C_{f}$ and $\operatorname{Re}_{\mathrm{x}}{ }^{-1 / 2} N u$ for various values of $\alpha, \gamma$, and $\beta$ when $\lambda=100, \delta=0.2$, and $\operatorname{Pr}=1$.

\begin{tabular}{|c|c|c|c|c|c|}
\hline \multicolumn{6}{|c|}{$\alpha=0.3(\alpha<1)$} \\
\hline \multicolumn{3}{|c|}{$\gamma=0.5$ (Casson fluid) } & \multicolumn{3}{|c|}{$\gamma \longrightarrow \infty$ (Newtonian fluid) } \\
\hline$\beta$ & $\mathrm{Re}_{x}^{1 / 2} C_{f}$ & $\mathrm{Re}_{x}^{-1 / 2} N u$ & $\beta$ & $R e_{x}^{1 / 2} C_{f}$ & $\mathrm{Re}_{x}^{-1 / 2} N u$ \\
\hline 0.0 & -1.471239 & 0.554472 & 0.0 & -0.849420 & 0.477993 \\
\hline 0.03 & -1.438959 & 0.558648 & 0.03 & -0.838336 & 0.483056 \\
\hline 0.06 & -1.380564 & 0.565924 & 0.06 & -0.821660 & 0.490370 \\
\hline 0.09 & -1.206177 & 0.586390 & 0.09 & -0.756075 & 0.513684 \\
\hline 0.1 & -1.075134 & 0.598926 & 0.1 & -0.704619 & 0.533512 \\
\hline \multicolumn{6}{|c|}{$\alpha=1.5(\alpha>1)$} \\
\hline \multicolumn{3}{|c|}{$\gamma=0.5$ (Casson fluid) } & \multicolumn{3}{|c|}{$\gamma \longrightarrow \infty$ (Newtonian fluid) } \\
\hline$\beta$ & $\mathrm{Re}_{x}^{1 / 2} C_{f}$ & $\operatorname{Re}_{x}^{-1 / 2} N u$ & $\beta$ & $\operatorname{Re}_{x}^{1 / 2} C_{f}$ & $\mathrm{Re}_{x}^{-1 / 2} N u$ \\
\hline 0.0 & 1.575351 & 0.764367 & 0.0 & 0.909529 & 0.792933 \\
\hline 1.0 & 1.471638 & 0.759695 & 1.0 & 0.871905 & 0.789131 \\
\hline 1.3 & 1.423248 & 0.757478 & 1.3 & 0.853617 & 0.787245 \\
\hline 1.6 & 1.355982 & 0.754340 & 1.6 & 0.828251 & 0.784612 \\
\hline 2.0 & 1.188822 & 0.746343 & 2.0 & 0.761718 & 0.777576 \\
\hline
\end{tabular}

Figures 2-4 show that the effect of the magnetic parameter $\beta$ on the velocity induced magnetic field and temperature profiles for both cases of Newtonian and non-Newtonian flows. It is observed that with $\alpha<1$ the velocity and induced magnetic field profiles increase by increasing the magnetic parameter $\beta$, whereas the opposite results hold with $\alpha>1$ for both cases. That is because the magnitude of skin friction coefficient decreases by increasing the magnetic parameter $\beta$ with $\alpha<1$. On the other hand, it is observed that with $\alpha>1$ the temperature profiles increase by increasing the magnetic parameter $\beta$, whereas the opposite results hold with $\alpha<1$ for both cases. Physically, the presence of a magnetic field generates a Lorentz force which diminishes the velocity field, while it enhances the temperature of the fluid. These results for Newtonian fluid are similar to those reported by Ali et al. [26]. Figures 5-7 show that the effects of the stretching parameter $\alpha$ on the velocity induced magnetic field and temperature profiles for both cases of flows. It is observed from Figure 5 that when $\alpha=1$ the velocity profiles for both cases of Newtonian and non-Newtonian flows coincide. In addition, it is observed that $f^{\prime}(\eta)=1$ and $f^{\prime \prime}(\eta)=0$ which means for this case that the surface and the fluid move with the same velocity. It is also noticed that the velocity profiles are increasing function with the values of the stretching parameter $\alpha>1$ whereas the reverse trend is observed with the values $\alpha<1$. It is found from Figures 6 and 7 that the induced magnetic field and temperature profiles reduce with an increase the stretching parameter $\alpha$ for both cases. It is noteworthy that the temperature profiles are lower in the case of nonNewtonian flow with increasing the stretching parameter than that in the case of Newtonian flow. Figures $8-10$ show that the effects of the reciprocal of magnetic Prandtl number 
TABLE 3: Variation of $\operatorname{Re}_{x}{ }^{1 / 2} C_{f}$ and $\operatorname{Re}_{\mathrm{x}}{ }^{-1 / 2} N u$ for various values of $\gamma$ and $\lambda$ when $\beta=0.05, \alpha=0.3, \delta=0.2$, and $\operatorname{Pr}=1$.

\begin{tabular}{lccccc}
\hline & $\gamma=0.5$ (Casson fluid) & & $\lambda$ & $\gamma \longrightarrow \infty$ (Newtonian fluid) \\
\hline$\lambda$ & $\operatorname{Re}_{x}^{1 / 2} C_{f}$ & $\mathrm{Re}_{x}^{-1 / 2} \mathrm{Nu}$ & $\mathrm{Re}_{x}^{1 / 2} C_{f}$ & -0.817375 \\
\hline 50 & -1.377330 & 0.566203 & 50 & -0.826710 & 0.492045 \\
\hline 100 & -1.403883 & 0.563065 & 100 & -0.833915 & 0.488214 \\
\hline 200 & -1.424976 & 0.560495 & 200 & -0.839708 & 0.485103 \\
\hline 400 & -1.442277 & 0.558274 & 400 & -0.844842 & 0.482508 \\
\hline 1000 & -1.457664 & 0.556272 & 1000 & 0.480146 \\
\hline
\end{tabular}

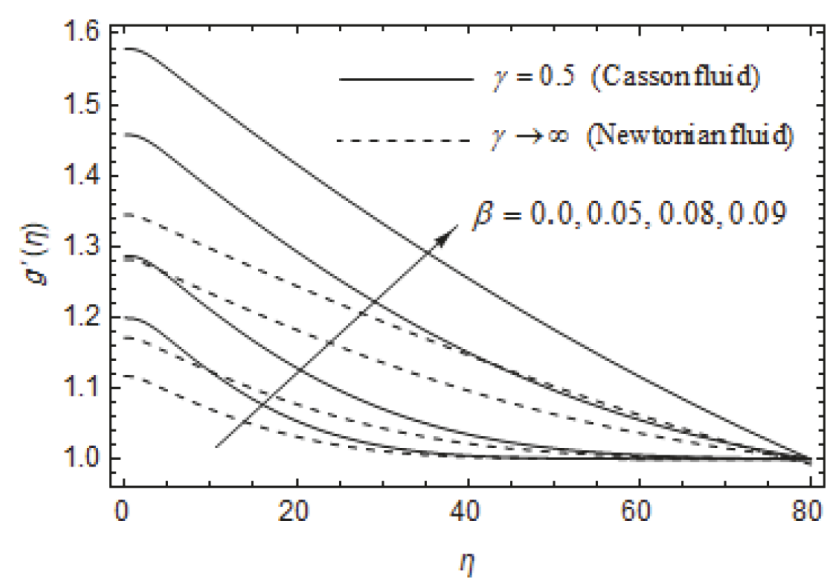

(a) Induced magnetic field profiles for various values of $\beta$ and $\gamma$ when $\chi=$ $E c=0.0, \lambda=100, \alpha=0.3, \delta=0.2$, and $\operatorname{Pr}=1$

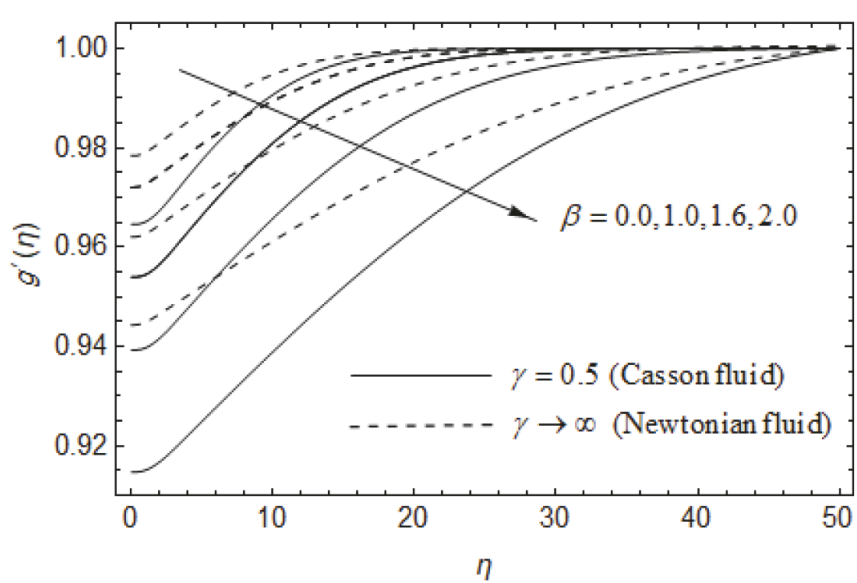

(b) Induced magnetic field profiles for various values of $\beta$ and $\gamma$ when $\chi=$ $E c=0.0, \lambda=100, \alpha=1.5, \delta=0.2$, and $\operatorname{Pr}=1$

FIGURE 3

TABLE 4: Variation of $\operatorname{Re}_{x}{ }^{-1 / 2} N u$ for various values of $\gamma$ and $\delta$ when $\beta=0.05, \lambda=100, \alpha=0.3$, and $\operatorname{Pr}=1$.

\begin{tabular}{lcc}
\hline \multicolumn{2}{r}{$\gamma=0.5$ (Casson fluid) } & $\gamma \rightarrow \infty$ (Newtonian fluid) \\
\hline$\delta$ & $\mathrm{Re}_{x}^{-1 / 2} \mathrm{Nu}$ & $\mathrm{Re}_{x}^{-1 / 2} \mathrm{Nu}$ \\
\hline-0.5 & 0.991088 & 0.960294 \\
\hline-0.2 & 0.830837 & 0.789346 \\
\hline 0.0 & 0.706984 & 0.653295 \\
\hline 0.2 & 0.562471 & 0.487522 \\
\hline 0.5 & 0.276985 & 0.115672 \\
\hline
\end{tabular}

$\lambda$ on the velocity induced magnetic field and temperature profiles for both cases of flows. It is observed from Figure 8 that the fluid velocity $f^{\prime}(\eta)$ reduces with an increase in the reciprocal of magnetic Prandtl number $\lambda$ for both cases. This is because the magnitude of skin friction coefficient increases by increasing the reciprocal of magnetic Prandtl number $\lambda$ for both cases. It is seen from Figure 9 that the induced magnetic field profiles $g^{\prime}(\eta)$ decrease greatly near the plate, whereas the situation is reversed for some values of $\lambda$ far away from the plate for both cases. It is observed from Figure 10 that the temperature profiles $\theta(\eta)$ increase slightly by increasing the reciprocal of magnetic Prandtl number $\lambda$. This agrees with the fact that the heat transfer rate at the surface diminishes with an increase in the magnetic Prandtl number $\lambda$ for both cases as depicted in Table 3. It is interesting to note that the effect of $\lambda$ demonstrates a more pronounced influence on the profiles of $f^{\prime}(\eta)$ and $g^{\prime}(\eta)$ in Casson fluid case than Newtonian fluid case. Further, the impact of $\lambda$ on the temperature is nearly equivalent in both cases. Figures 11-13 elucidate the effects of Casson fluid parameter $\gamma$, on the velocity, induced magnetic field and temperature profiles for both cases. It is noticed from Figures 11 and 12 that both the velocity and the induced magnetic field profiles are decreasing function of the Casson fluid parameter $\gamma$, for both cases. It is seen from Figure 13 that the temperature distributions enhance with an increase in the parameter $\gamma$. That is because an increase in $\gamma$ with the presence of magnetic parameter leads to an increase in plastic dynamic viscosity that creates resistance the fluid motion and enhances the temperature field. Figure 14 illustrates the effects of the heat generation/absorption parameter $\delta$ on the temperature profiles for both cases. The heat generation source $\delta>0$ leads to increase in the temperature profiles in the boundary layer, whereas opposite effect is observed for heat absorption $\delta<0$ for both cases. For Newtonian fluid, the temperature distributions are more pronounced with a rise in $\delta$ than non-Newtonian fluid. The influences of the slip parameter $\chi$ on the velocity $f^{\prime}(\eta)$ induced magnetic field $g^{\prime}(\eta)$ and temperature profiles $\theta(\eta)$ are represented in Figures 15-17. It is noted from Figures $15-17$ that the velocity and induced magnetic field profiles reduce with an increase in slip parameter, whereas the reverse trend is seen for temperature 


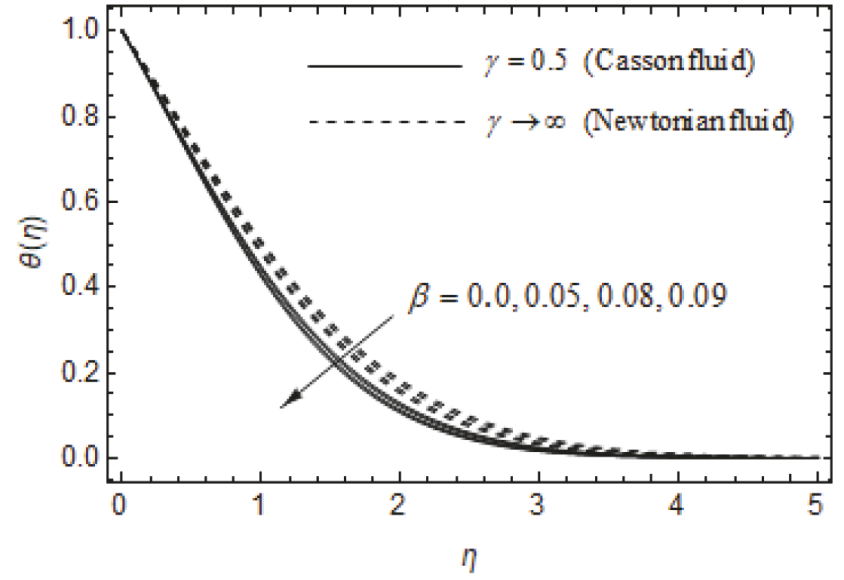

(a) Temperature profiles for various values of $\beta$ and $\gamma$ when $\lambda=100, \alpha=0.3$, $\delta=0.2, \chi=E c=0.0$, and $\operatorname{Pr}=1$

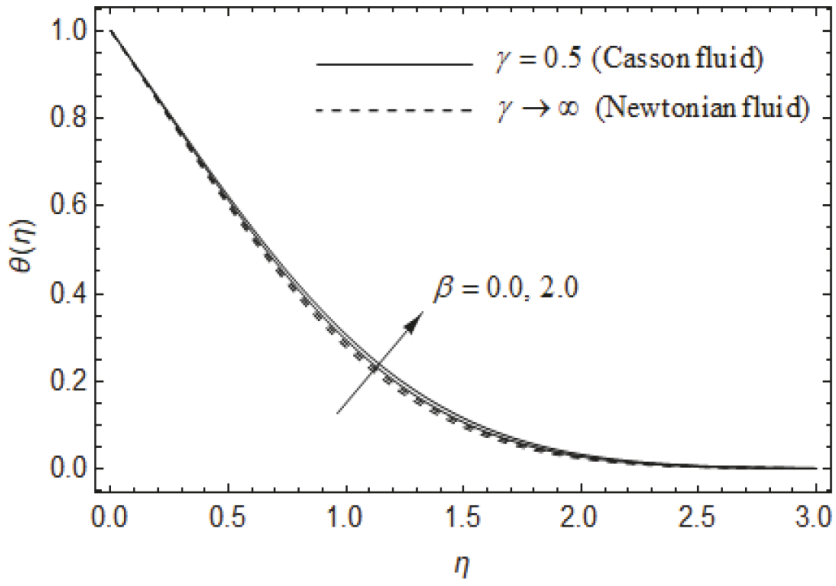

(b) Temperature profiles for various values of $\beta$ and $\gamma$ when $\lambda=100, \alpha=1.5$, $\delta=0.2, \chi=E c=0.0$, and $\operatorname{Pr}=1$

Figure 4

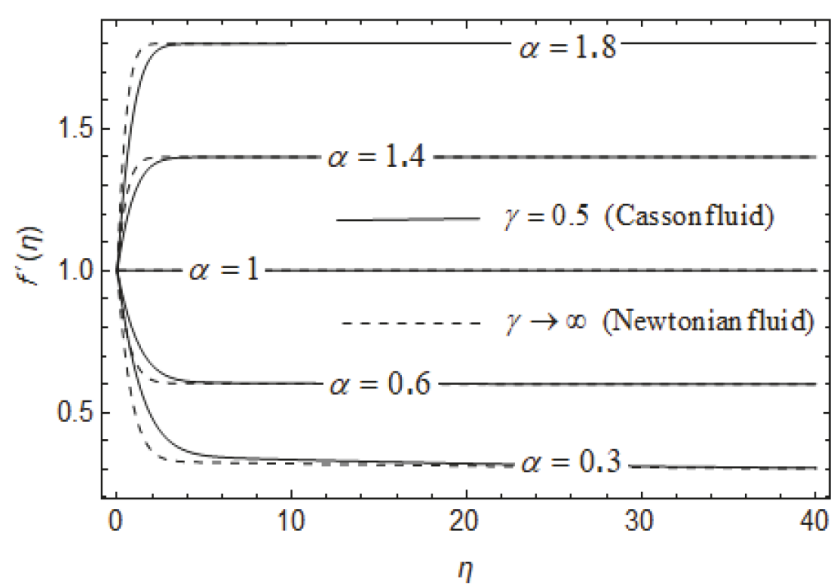

Figure 5: Velocity profiles for various values of $\alpha$ and $\gamma$ when $\beta=$ $0.05, \lambda=100, \delta=0.2, \chi=E c=0.0$, and $\operatorname{Pr}=1$.

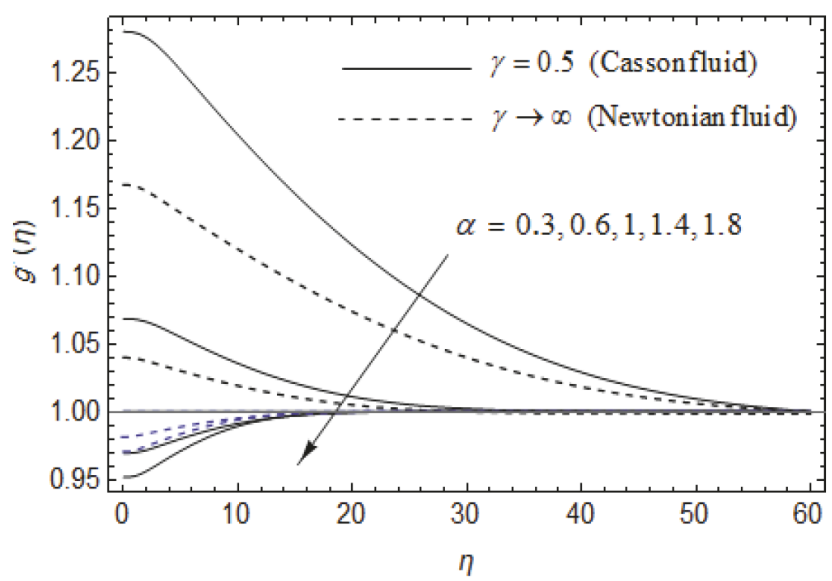

Figure 6: Induced magnetic field profiles for various values of $\alpha$ and $\gamma$ when $\beta=0.05, \lambda=100, \delta=0.2, \chi=E c=0.0$, and $\operatorname{Pr}=1$.

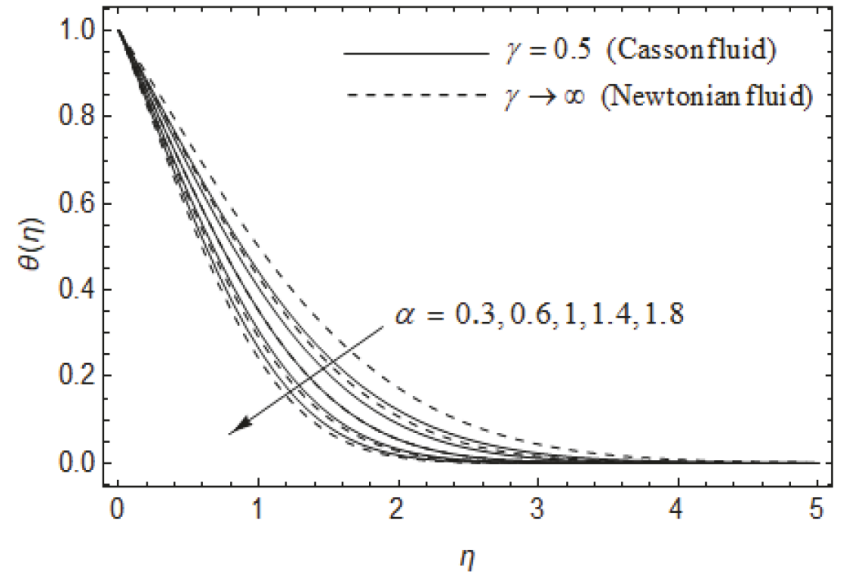

Figure 7: Temperature profiles for various values of $\alpha$ and $\gamma$ when $\beta=0.05, \lambda=100, \delta=0.2, \chi=E c=0.0$, and $\operatorname{Pr}=1$.

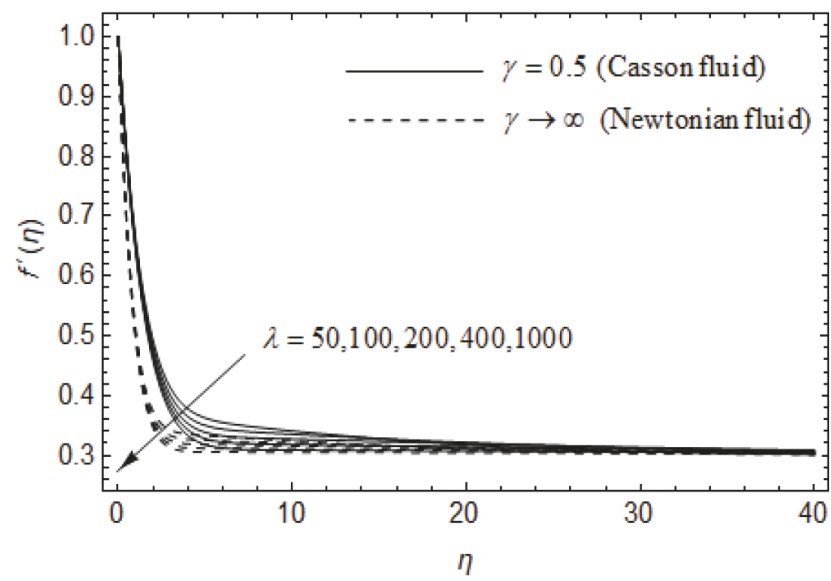

FIGURE 8: Velocity profiles for various values of $\lambda$ and $\gamma$ when $\beta=$ $0.05, \alpha=0.2, \delta=0.2, \chi=E c=0.0$, and $\operatorname{Pr}=1$. 


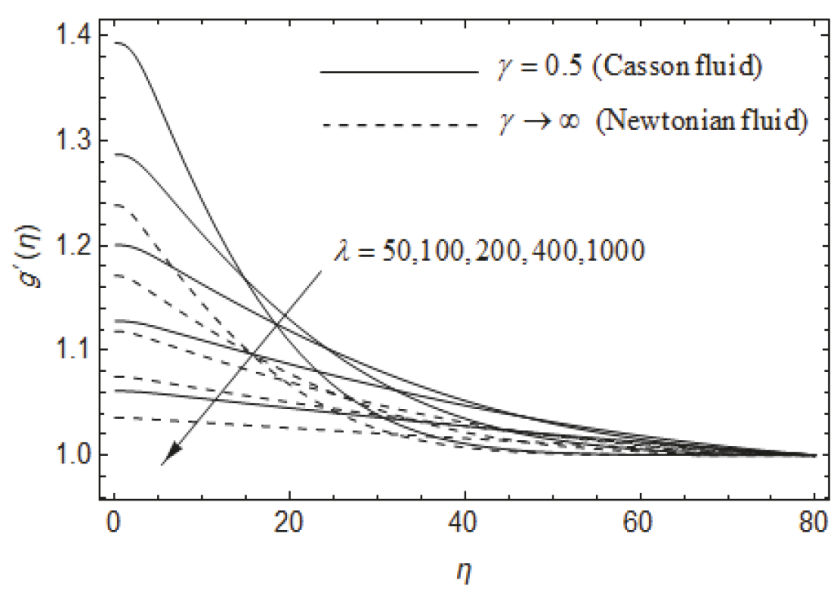

FIgURE 9: Induced magnetic field profiles for various values of $\lambda$ and $\gamma$ when $\beta=0.05, \alpha=0.2, \delta=0.2, \chi=E c=0.0$, and $\operatorname{Pr}=1$.

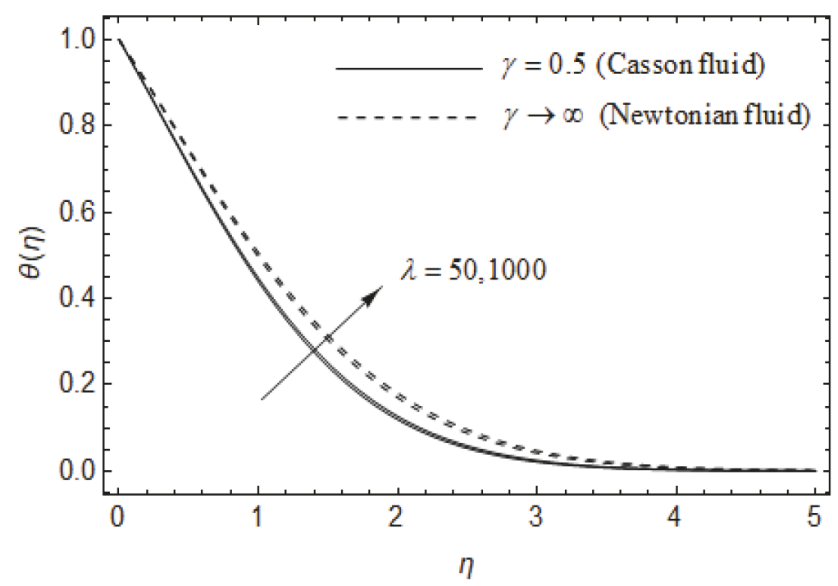

FIgURE 10: Temperature profiles for various values of $\lambda$ and $\gamma$ when $\beta=0.05, \alpha=0.2, \delta=0.2, \chi=E c=0.0$, and $\operatorname{Pr}=1$.

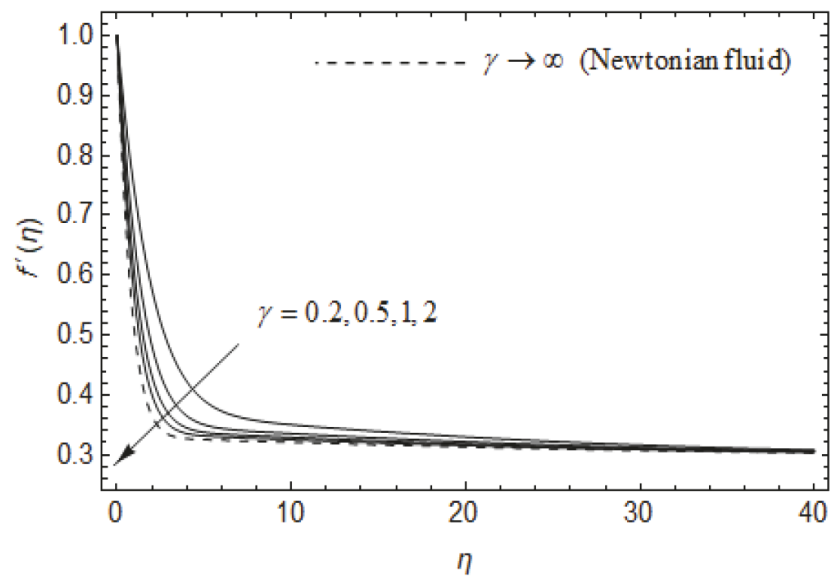

FIGURE 11: Velocity profiles for various values of $\gamma$ when $\beta=0.05$, $\lambda=100, \alpha=0.2, \delta=0.2, \chi=E c=0.0$, and $\operatorname{Pr}=1$.

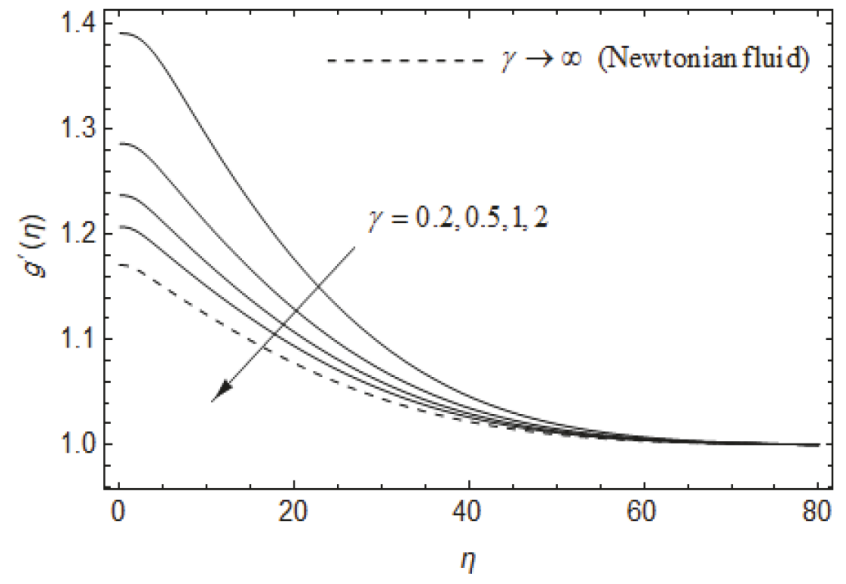

FIGURE 12: Induced magnetic field profiles for various values of $\gamma$ when $\beta=0.05, \lambda=100 \alpha=0.2, \delta=0.2, \chi=E c=0.0$, and $\operatorname{Pr}=1$.

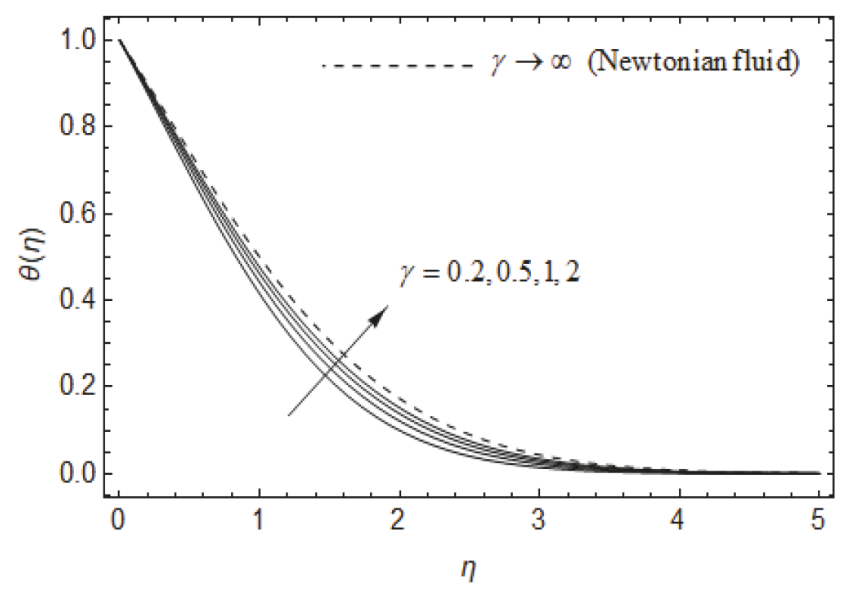

FIGURE 13: Temperature profiles for various values of $\gamma$ when $\beta=$ $0.05, \lambda=100, \alpha=0.2, \delta=0.2, \chi=E c=0.0$, and $\operatorname{Pr}=1$.

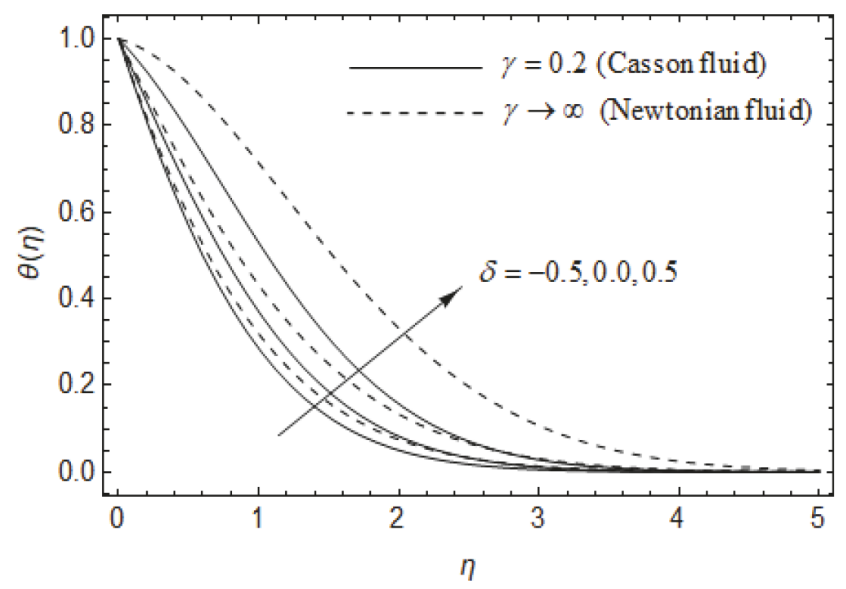

FIGURE 14: Temperature profiles for various values of $\gamma$ and $\delta$ when $\beta=0.05, \lambda=100, \alpha=0.2, \chi=E c=0.0$, and $\operatorname{Pr}=1$. 


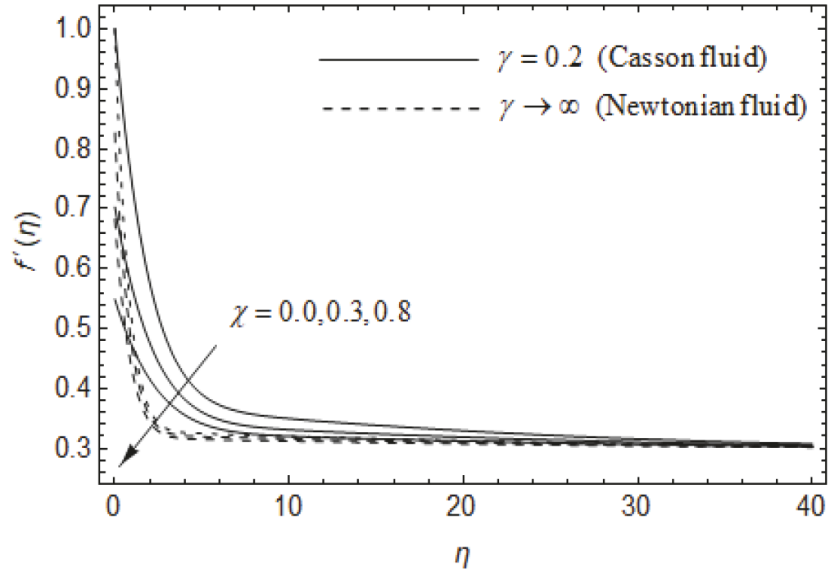

FIGURE 15: Velocity profiles for various values of $\chi$ when $\beta=0.05$, $\lambda=100, \alpha=0.3, \delta=0.5, E c=0.1$, and $\operatorname{Pr}=1$.

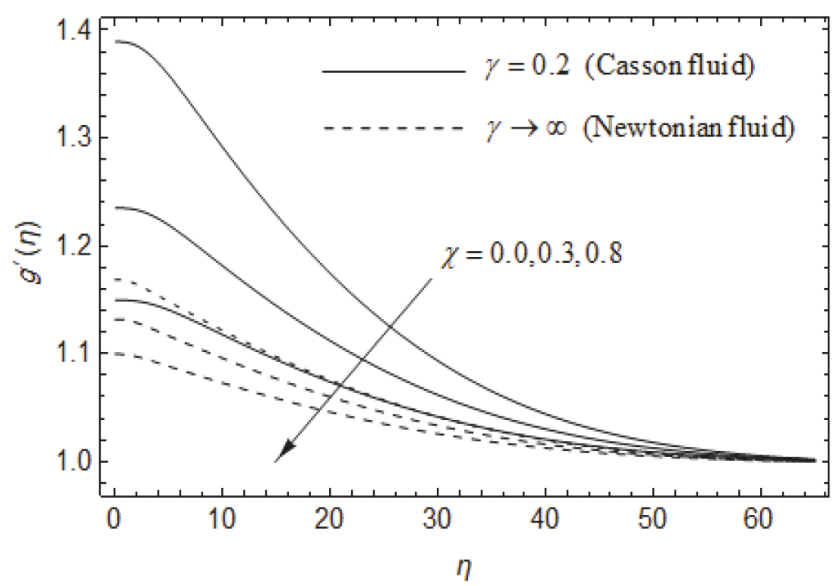

FIGURE 16: Induced magnetic field profiles for various values of $\chi$ when $\beta=0.05, \lambda=100, \alpha=0.3, \delta=0.5, E c=0.1$, and $\operatorname{Pr}=1$.

profiles for both cases. This is due to the fact that an increase in the slip factor generates the friction force which allows more fluid to slip past the sheet, the flow decelerates, and the temperature fields' boost attributable to the occurrence of the force. The influences of the Eckert number on the temperature fields for both cases are portrayed in Figure 18. It is noticed from Figure 18 that the temperature fields enhance with an increase in Eckert number. Physically, Eckert number is the ratio of kinetic energy to enthalpy. Therefore, an increase in Eckert number causes the conversion of kinetic energy into internal energy by work that is done against the viscous fluid stresses. It is noteworthy that the temperature of the fluid is higher in the case of non-Newtonian fluid with a rise in $E c$ than that in the case of the Newtonian fluid.

\section{Conclusions}

The MHD boundary layer flow and heat transfer of a nonNewtonian Casson fluid in the neighborhood of a stagnation point over a stretching surface are numerically investigated.

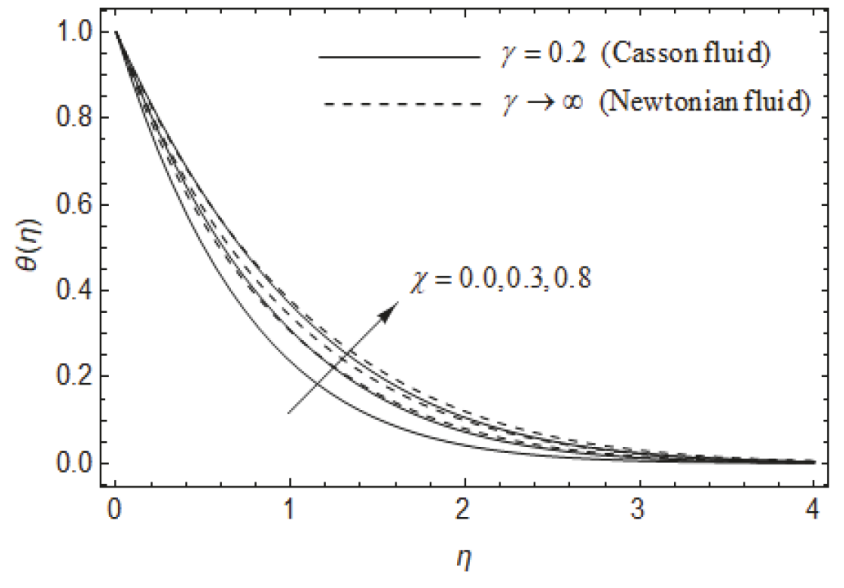

FIGURE 17: Temperature field profiles for various values of $\chi$ when $\beta=0.05, \lambda=100, \alpha=0.3, \delta=0.5, E c=0.1$, and $\operatorname{Pr}=1$.

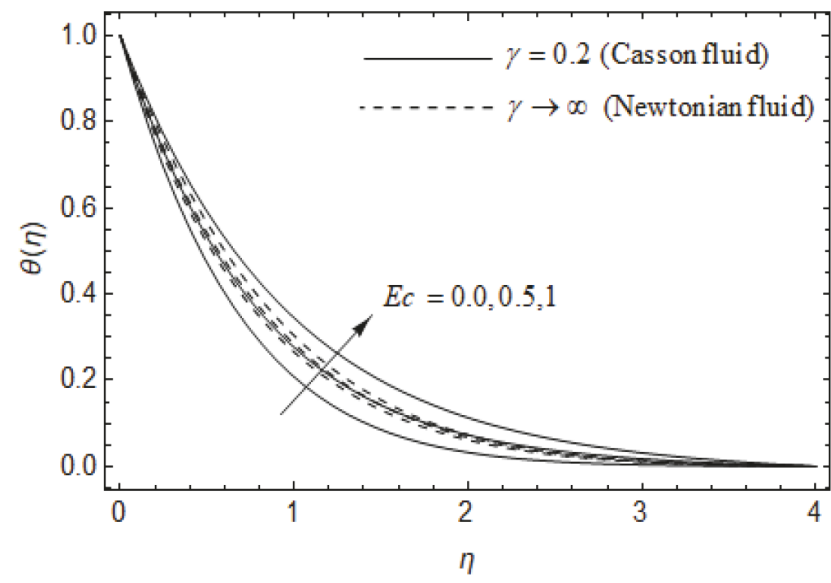

FIGURE 18: Temperature field profiles for various values of $E c$ when $\beta=0.05, \lambda=100, \alpha=0.3, \delta=0.5, E c=0.1$, and $\operatorname{Pr}=1$.

The results of this article are indicated a novel aspect of Casson flow that utilizes the combined influences of the induced magnetic field, viscous dissipation, magnetic dissipation, and slips flow phenomena. The results are discussed in graphs and tables. The main conclusions of the current study are as follows:

(1) Impacts of the most physical parameters are markedly pronounced for Casson fluid when compared to Newtonian flow.

(2) The magnitude of skin friction coefficient is reduced, whereas the rate of heat transfer is enhanced with an increase in magnetic parameter $\beta$ and $\alpha<1$ for both fluid cases.

(3) The skin friction coefficient and the rate of heat transfer are diminished by increasing the values of magnetic parameter with $\alpha>1$ for both fluid cases.

(4) The magnitude of skin friction coefficient is boosted, whereas the rate of heat transfer is depreciated with an 
increase in reciprocal of the magnetic Prandtl number for both fluid cases.

(5) The rate of heat transfer is augmented with heat absorption $\delta<0$, whereas the opposite trend is observed with heat generation $\delta>0$ for both fluid cases.

(6) The velocity and the induced magnetic field distribution are depressed, whereas the temperature distribution is elevated with an increase in Casson fluid parameter.

(7) The velocity and induced magnetic field distribution are reduced with an increase in slip parameter.

(8) The temperature distribution is enhanced with an increase in Eckert number and slip parameter.

\section{Data Availability}

The data used to support the findings of this study are available from the corresponding author upon request.

\section{Disclosure}

Mohamed Abd El-Aziz and Ahmed A. Afify Permanent address is as follows: Department of Mathematics, Faculty of Science, Helwan University, Ain Helwan, P.O. Box 11795, Cairo, Egypt.

\section{Conflicts of Interest}

The authors declare that there are no conflicts of interest regarding the publication of this article.

\section{Acknowledgments}

The authors would like to express their gratitude to King Khalid University, Saudi Arabia, for providing administrative and technical support.

\section{References}

[1] K. Hiemenz, "Die Grenzschicht an einem in den gleichfiirmingen Flussigkeitsstrom eingetauchten geraden Kreiszylinder," Dinglers Polytechnisches Journal, vol. 326, pp. 321-410, 1911.

[2] F. Homann, "Der Einfluß großer Zähigkeit bei der Strömung um den Zylinder und um die Kugel," ZAMM - Journal of Applied Mathematics and Mechanics / Zeitschrift für Angewandte Mathematik und Mechanik, vol. 16, no. 3, pp. 153-164, 1936.

[3] I. Pop, "Mhd Flow near an Asymmetric Plane Stagnation Point," ZAMM - Journal of Applied Mathematics and Mechanics / Zeitschrift für Angewandte Mathematik und Mechanik, vol. 63, no. 11, pp. 580-581, 1983.

[4] P. D. Ariel, "Hiemenz flow in hydromagnetics," Acta Mechanica, vol. 103, no. 1-4, pp. 31-43, 1994.

[5] A. J. Chamkha, "Hydromagnetic plane and axisymmetric flow near a stagnation point with heat generation," International Communications in Heat and Mass Transfer, vol. 25, no. 2, pp. 269-278, 1998.

[6] U. Khan, N. Ahmed, S. I. Khan, and S. T. Mohyud-din, "Thermo-diffusion effects on MHD stagnation point flow towards a stretching sheet in a nanofluid," Propulsion and Power Research, vol. 3, no. 3, pp. 151-158, 2014.

[7] K. Anantha Kumar, J. V. Ramana Reddy, N. Sandeep, and V. Sugunamma, "Influence of thermal radiation on stagnation flow towards a stretching sheet with induced magnetic field," Advances in Physics Theories and Applications, vol. 53, pp. 2328, 2016.

[8] M. Waleed Ahmed Khan, M. Waqas, M. Ijaz Khan, A. Alsaedi, and T. Hayat, "MHD stagnation point flow accounting variable thickness and slip conditions," Colloid and Polymer Science, vol. 295, no. 7, pp. 1201-1209, 2017.

[9] N. T. Eldabe and M. Y. Abou-zeid, "Homotopy perturbation method for MHD pulsatile non-Newtonian nanofluid flow with heat transfer through a non-Darcy porous medium," Journal of the Egyptian Mathematical Society, vol. 25, no. 4, pp. 375-381, 2017.

[10] A. M. Siddiqui, A. Zeb, Q. K. Ghori, and A. Benharbit, "Homotopy perturbation method for heat transfer flow of a third grade fluid between parallel plates," Chaos, Solitons \& Fractals, vol. 36, no. 1, pp. 182-192, 2008.

[11] N. T. M. El-Dabe, A. A. Shaaban, M. Y. Abou-Zeid, and H. A. Ali, "Magnetohydrodynamic non-Newtonian nanofluid flow over a stretching sheet through a non-Darcy porous medium with radiation and chemical reaction," Journal of Computational and Theoretical Nanoscience, vol. 12, no. 12, pp. 5363-5371, 2015.

[12] N. T. M. El-dabe, M. Y. Abou-zeid, and Y. M. Younis, "Magnetohydrodynamic peristaltic flow of Jeffry nanofluid with heat transfer through a porous medium in a vertical tube," Applied Mathematics \& Information Sciences, vol. 11, no. 4, pp. 1097-1103, 2017.

[13] B. Ramandevi, J. V. R. Reddy, V. Sugunamma, and N. Sandeep, "Combined influence of viscous dissipation and non-uniform heat source/sink on MHD non-Newtonian fluid flow with Cattaneo-Christov heat flux," Alexandria Engineering Journal, 2016.

[14] H. I. Andersson and V. Kumaran, "On sheet-driven motion of power-law fluids," International Journal of Non-Linear Mechanics, vol. 41, no. 10, pp. 1228-1234, 2006.

[15] A. A. Afify, "Some new exact solutions for MHD aligned creeping flow and heat transfer in second grade fluids by using Lie group analysis," Nonlinear Analysis. Theory, Methods and Applications. An International Multidisciplinary Journal, vol. 70, no. 9, pp. 3298-3306, 2009.

[16] S. Nadeem, R. Mehmood, and N. S. Akbar, "Optimized analytical solution for oblique flow of a Casson-nano fluid with convective boundary conditions," International Journal of Thermal Sciences, vol. 78, pp. 90-100, 2014.

[17] A. V. Mernone, J. N. Mazumdar, and S. K. Lucas, "A mathematical study of peristaltic transport of a Casson fluid," Mathematical and Computer Modelling, vol. 35, no. 7-8, pp. 895-912, 2002.

[18] S. A. Shehzad, T. Hayat, M. Qasim, and S. Asghar, "Effects of mass transfer on MHD flow of Casson fluid with chemical reaction and suction," Brazilian Journal of Chemical Engineering, vol. 30, no. 1, pp. 187-195, 2013.

[19] M. A. El-Aziz and A. A. Afify, "Effects of Variable Thermal Conductivity with Thermal Radiation on MHD Flow and Heat Transfer of Casson Liquid Film Over an Unsteady Stretching Surface," Brazilian Journal of Physics, vol. 46, no. 5, pp. 516-525, 2016.

[20] J. V. Ramana Reddy, V. Sugunamma, and N. Sandeep, "Enhanced heat transfer in the flow of dissipative non-Newtonian 
Casson fluid flow over a convectively heated upper surface of a paraboloid of revolution," Journal of Molecular Liquids, vol. 229, pp. 380-388, 2017.

[21] K. Anantha Kumar, J. V. Ramana Reddy, N. Sandeep, and V. Sugunamma, "Dual solutions for thermo diffusion and diffusion thermo effects on 3D MHD casson fluid flow over a stretching surface," Research Journal of Pharmacy and Technology, vol. 9, no. 8, pp. 1187-1194, 2016.

[22] K. A. Khan, A. R. Butt, and N. Raza, "Effects of heat and mass transfer on unsteady boundary layer flow of a chemical reacting Casson fluid," Results in Physics, vol. 8, pp. 610-620, 2018.

[23] A. Kumar and A. K. Singh, "Unsteady MHD free convective flow past a semi-infinite vertical wall with induced magnetic field," Applied Mathematics and Computation, vol. 222, pp. 462471, 2013.

[24] O. A. Bég, A. Y. Bakier, V. R. Prasad, J. Zueco, and S. K. Ghosh, "Nonsimilar, laminar, steady, electrically-conducting forced convection liquid metal boundary layer flow with induced magnetic field effects," International Journal of Thermal Sciences, vol. 48, no. 8, pp. 1596-1606, 2009.

[25] S. K. Ghosh, O. A. Bég, and J. Zueco, "Hydromagnetic free convection flow with induced magnetic field effects," Meccanica, vol. 45, no. 2, pp. 175-185, 2010.

[26] F. M. Ali, R. Nazar, N. M. Arifin, and I. Pop, "MHD stagnationpoint flow and heat transfer towards stretching sheet with induced magnetic field," Applied Mathematics and MechanicsEnglish Edition, vol. 32, no. 4, pp. 409-418, 2011.

[27] Z. Iqbal, E. N. Maraj, E. Azhar, and Z. Mehmood, "Framing the performance of induced magnetic field and entropy generation on $\mathrm{Cu}$ and $\mathrm{TiO} 2$ nanoparticles by using Keller box scheme," Advanced Powder Technology, vol. 28, no. 9, pp. 2332-2345, 2017.

[28] G. S. Beavers and D. D. Joseph, "Boundary conditions at a numerically permeable wall," Journal of Mechanics, vol. 30, pp. 197-207, 1967.

[29] A. A. Afify, M. J. Uddin, and M. Ferdows, "Scaling group transformation for MHD boundary layer flow over permeable stretching sheet in presence of slip flow with Newtonian heating effects," Applied Mathematics and Mechanics-English Edition, vol. 35, no. 11, pp. 1375-1386, 2014.

[30] M. J. Uddin, O. A. Bég, M. N. Uddin, and A. I. M. Ismail, "Numerical solution of thermo-solutal mixed convective slip flow from a radiative plate with convective boundary condition," Journal of Hydrodynamics, vol. 28, no. 3, pp. 451-461, 2016.

[31] J. V. Ramana Reddy, V. Sugunamma, and N. Sandeep, "Effect of frictional heating on radiative ferrofluid flow over a slendering stretching sheet with aligned magnetic field," The European Physical Journal Plus, vol. 132, no. 1, 2017.

[32] J. V. Ramana Reddy, V. Sugunamma, N. Sandeep, and K. Anantha Kumar, "Influence of non uniform heat source/sink on MHD nano fluid flow past a slendering stretching sheet with slip effects," The Global Journal of Pure and Applied Mathematics (GJPAM), vol. 12, no. 1, pp. 247-254, 2016.

[33] E. Hosseini, G. B. Loghmani, M. Heydari, and M. M. Rashidi, "Numerical investigation of velocity slip and temperature jump effects on unsteady flow over a stretching permeable surface," The European Physical Journal Plus, vol. 132, no. 2, 2017.

[34] N. T. M. Eldabe and M. G. E. Salwa, "Heat transfer of MHD nonNewtonian Casson fluid flow between two rotating cylinders," Journal of the Physical, vol. 64, pp. 41-64, 1995.

[35] T. G. Cowling, Magnetohydrodynamics, Interscience Tracts on Physics and Astronomy, No. 4, Interscience Publishers, Inc., New York; Interscience Publishers, Ltd., London, 1957.
[36] F. M. Ali, R. Nazar, N. M. Arifin, and I. Pop, "MHD boundary layer flow and heat transfer over a stretching sheet with induced magnetic field," Heat and Mass Transfer, vol. 47, no. 2, pp. 155162,2011

[37] D. Pal and G. Mandal, "MHD convective stagnation-point flow of nanofluids over a non-isothermal stretching sheet with induced magnetic field," Meccanica, vol. 50, no. 8, pp. 20232035, 2015.

[38] T. R. Mahapatra and A. S. Gupta, "Heat transfer in stagnationpoint flow towards a stretching sheet," Heat and Mass Transfer, vol. 38, no. 6, pp. 517-521, 2002.

[39] A. Ishak, R. Nazar, and I. Pop, "Mixed convection boundary layers in the stagnation-point flow toward a stretching vertical sheet," Meccanica, vol. 41, no. 5, pp. 509-518, 2006. 


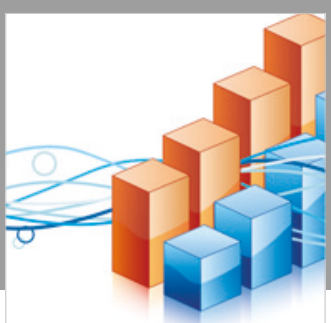

Advances in

Operations Research

\section{-n-m}
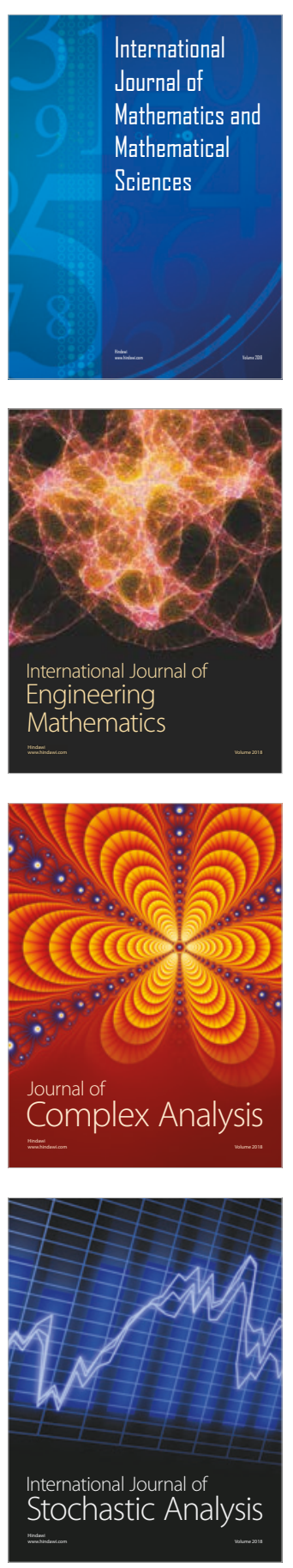
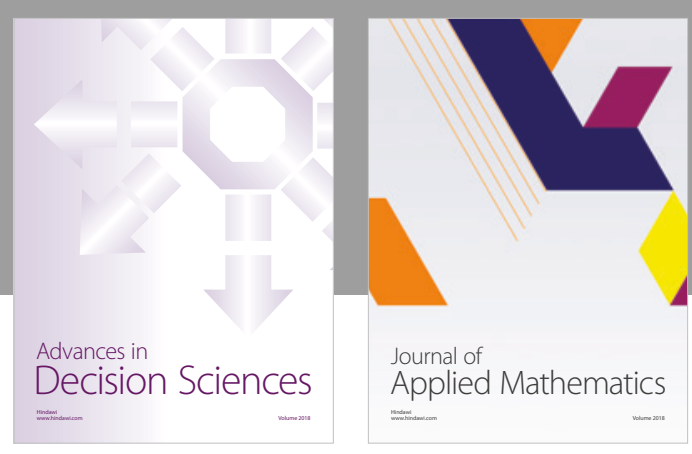

Journal of

Applied Mathematics
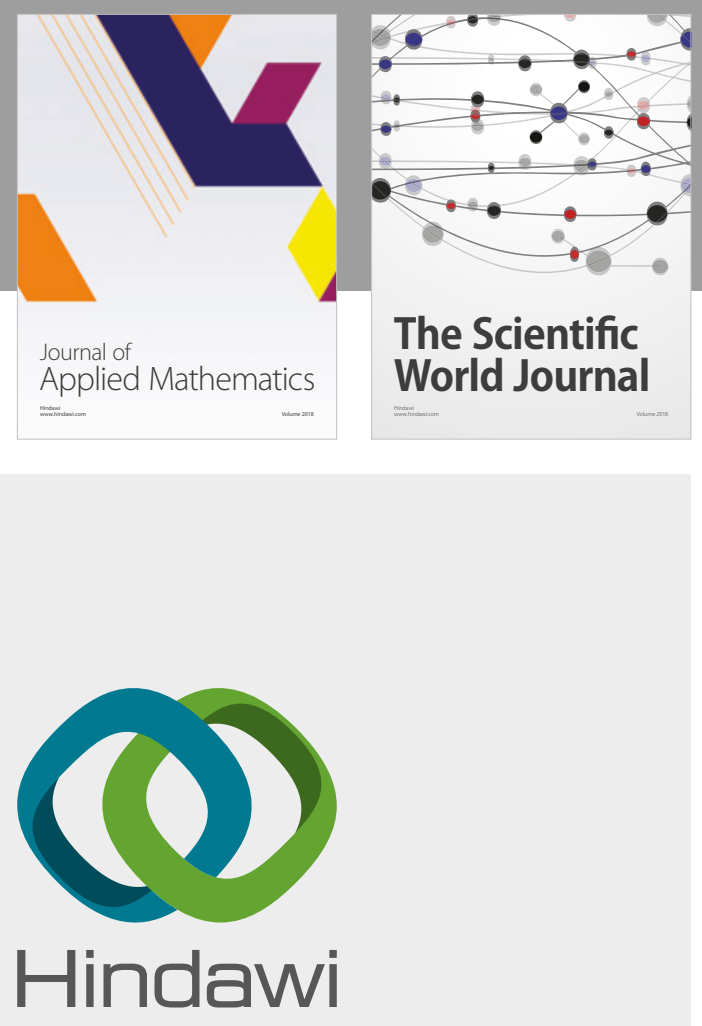

Submit your manuscripts at

www.hindawi.com

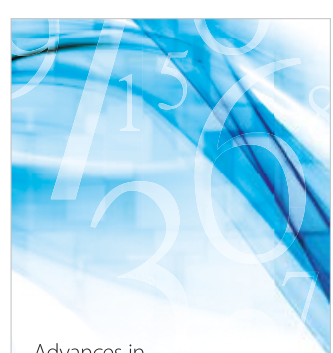

Advances in
Numerical Analysis
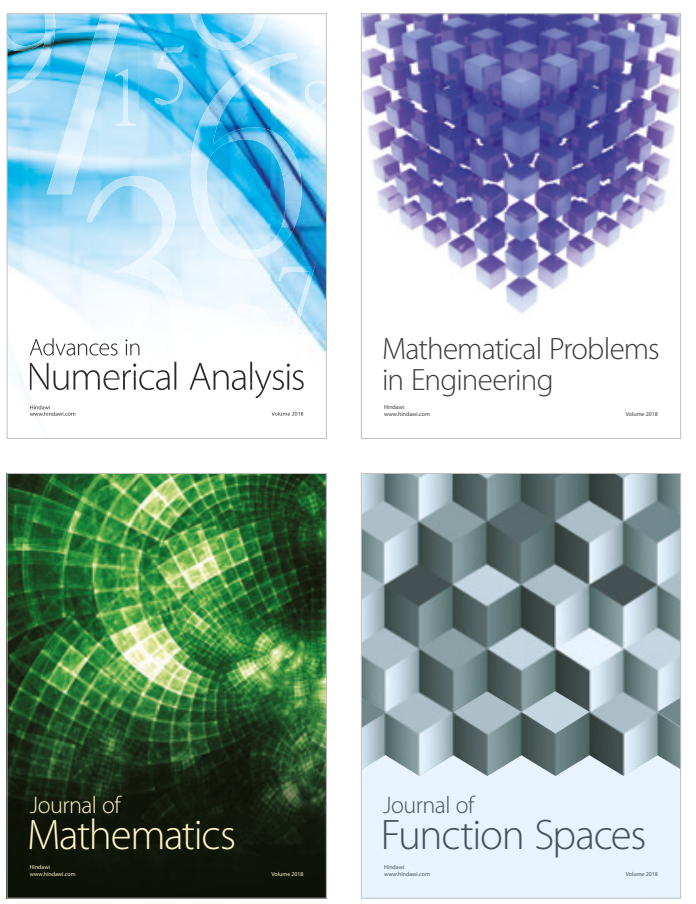

Mathematical Problems in Engineering

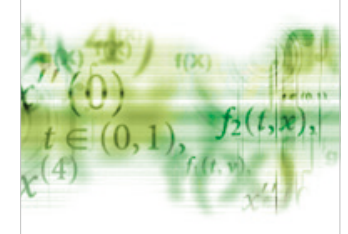

International Journal of

Differential Equations

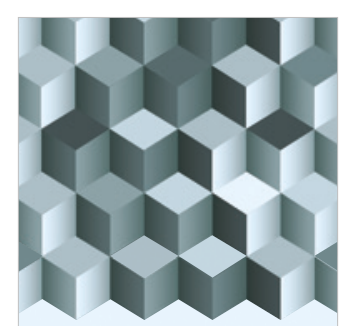

Journal of

Function Spaces

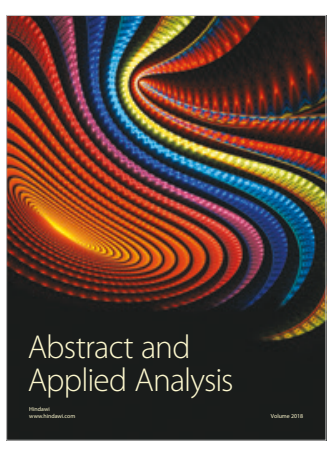

The Scientific

World Journal

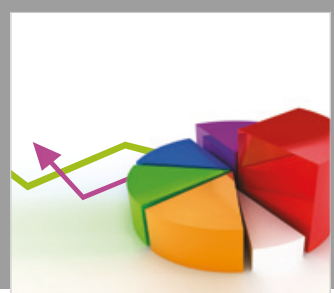

Journal of

Probability and Statistics
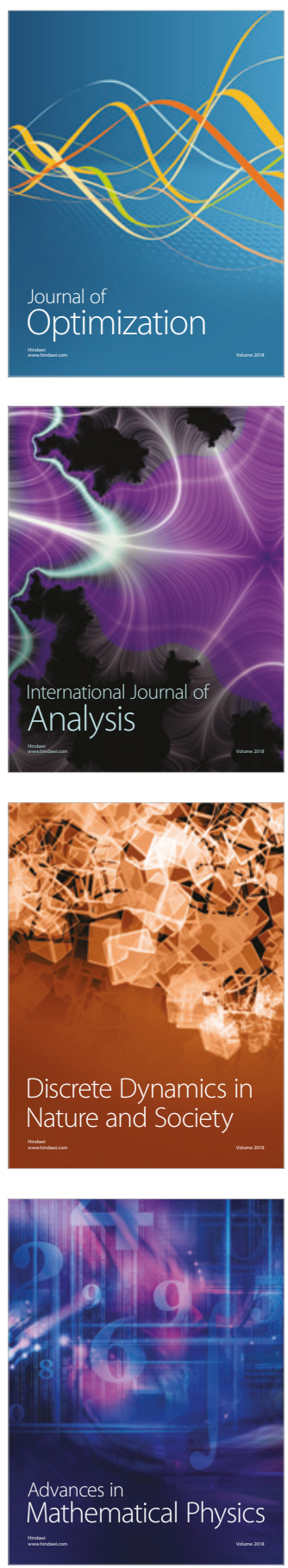